\title{
Effect of Contrast Sensitivity on Age Related Macular Degeneration
}

\author{
Partha Haradhan Chowdhury ${ }^{1 *}$ and Brinda Haren Shah ${ }^{2}$ \\ 1M.Optom, Associate Professor, Principal, Department of Optometry, Shree Satchandi \\ Jankalyan Samiti Netra Prasikshan Sansthan, Pauri, Affiliated to Uttarakhand State \\ Medical Faculty, Dehradun, India
}

\section{Research Article}

Volume 3 Special Issue 2

Received Date: September 10, 2018

Published Date: October 22, 2018

${ }^{2}$ M.Optom, Guest Lecturer, Department of Optometry, Shree Satchandi Jankalyan Samiti Netra Prasikshan Sansthan, Pauri, Affiliated to Uttarakhand State Medical Faculty, Dehradun, India

*Corresponding author: M. Optom, Associate Professor, Principal, Department of Optometry, Shree Satchandi Jankalyan Samiti Netra Prasikshan Sansthan, Pauri, Affiliated to Uttarakhand State Medical Faculty, Dehradun, India, Email: optometrypublish@gmail.com

\section{Abstract}

Purpose: Aim of the present study is to evaluate the contrast sensitivity in subjects of Age Related Macular Degeneration. Methods: A pilot, cross sectional, observational study was performed at tertiary eye care centers. Subjects with Age Related Macular Degeneration and age group of 40 to 65 were included in the study. Ocular as well as systemic pathology were excluded. Contrast sensitivity was assessed with Pelli Robson Chart.

Results: 83 subjects were included in the study. Out of that $57 \%$ were males and $43 \%$ were females. Mean contrast sensitivity is considered for statistical analysis. It shows that Contrast Sensitivity is deteriorated to 1.5 in cases of Age Related Macular Degeneration.

Conclusions: Contrast Sensitivity deteriorates in the presence of Age Related Macular Degeneration.

Keywords: Contrast Sensitivity; Age Related Macular Degeneration

\section{Introduction}

It is a bilateral age related problem and usually it is characterized by sub retinal neovascular membrane (SRNVM). In ARMD, new blood vessels are present under the retina and macular area and it usually cause blindness. Here, central vision is affected due to blood vessels are present under the macular area. Colloid bodies (drusen) are also present at macular area. In the foveal area cone cell density is much more as compared to para foveal region. So, in ARMD, cone cells will be destroyed due to SRNVMs and Drusen. As cone cells are solely responsible for Contrast Sensitivity, there are chances of deterioration of Contrast Sensitivity in these cases. Density of cone cells are much more in foveal area and difference between two cone cells are much more as 
compared to parafoveal area. So, in cases of ARMD, there are lots of chances of deterioration of Contrast Sensitivity [1].

\section{Methodology}

A pilot, cross sectional and observational study was performed in tertiary eye care centers in the period of 1 year. All the subjects are enrolled with informed consent. Subjects having Age Related Macular Degeneration are included in the study. Age group of 40 to 65 years were included in the study. Subjects having any other ocular pathology including retinal pathology except Age Related Macular Degeneration were excluded from the study. Subjects with systemic disorders were also excluded. Full refractive correction along with Slit lamp examination and detailed fundus evaluation was performed in each and every patient. Contrast sensitivity was assessed using Pelli Robson Contrast Sensitivity Chart. Data analysis was performed with SPSS software 20 and Microsoft Office Excel 10 [2].

\section{Results}

A total of 83 subjects were included in the study. Figure 1 shows age wise distribution of the subjects. Figure 2 shows gender distribution. Out of 83 subjects, 47 subjects were male and 36 subjects were female. Mean contrast sensitivity of 83 subjects were considered for statistical analysis. Normal value of Contrast Sensitivity is 1.95. Figure 3 shows effect on contrast sensitivity in Age Related Macular Degeneration Subjects. It shows that mean contrast sensitivity was deteriorated to 1.5 .

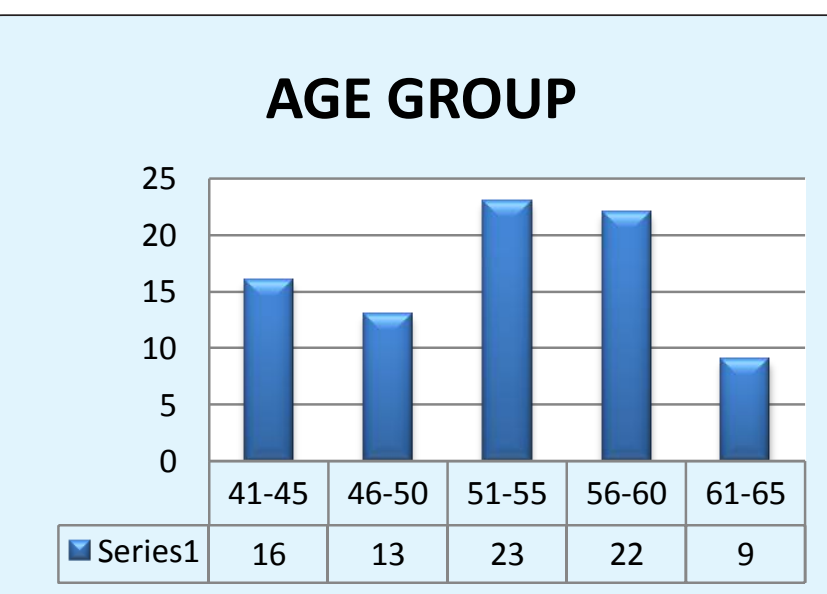

Figure 1: Shows Age Wise Distribution of Subjects.

\section{GENDER}

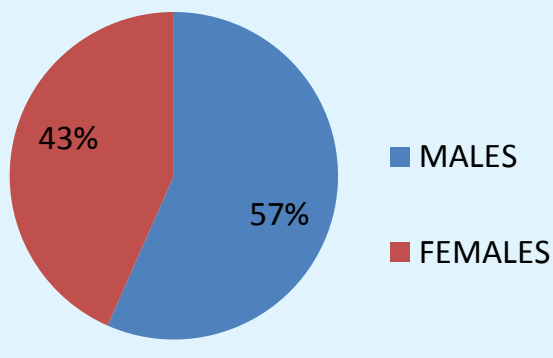

Figure 2: Shows Gender Wise Distribution of Subjects.

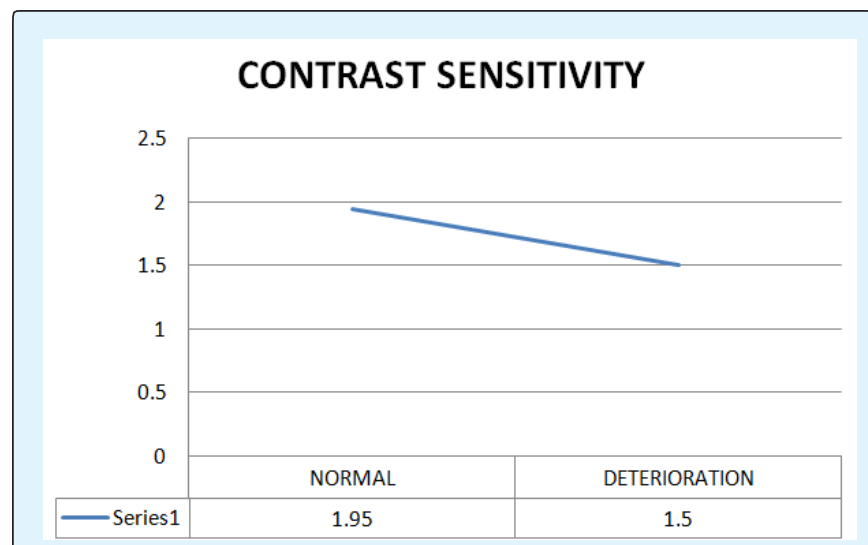

Figure 3: Shows Deterioration of Contrast Sensitivity in Armd Subjects.

\section{Discussion}

In case of Age Related Macular Degeneration, the colloid bodies are present at the foveal area. So, there are lots of chances to deteriorate the visual acuity and contrast sensitivity. Contrast sensitivity is deteriorated due to the damage in cone cells. In presence of Age Related Macular Degeneration, cone cells get damaged which will deteriorate the Contrast Sensitivity. As per the study, it is seen that average contrast sensitivity is deteriorated to 1.5 . So, there is a strong co relation between Contrast Sensitivity and ARMD [3,4].

\section{Conclusion}

Contrast Sensitivity deteriorates in the presence of Age Related Macular Degeneration. 


\section{Open Access Journal of Ophthalmology}

\section{References}

1. W E Alberti, G Richard, RH Sagerman (2012) AgeRelated Macular Degeneration: Current Treatment Concepts.

2. Brad Bowling (2016) Kanski's Clinical Ophthalmology E-Book: A Systematic Approach. $8^{\text {th }}$ (Edn.).
3. Sihota, Radhika Tandon (2018) Parson's Diseases of the Eye. 22nd (Edn.).

4. Samar K Basak (2009) Clinical Ophthalmology.

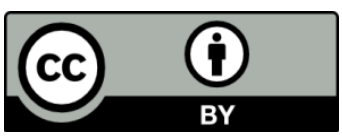

